\title{
Energia e Emissões na Produção de Óleo de Palma / Dendê (Elaeis guineensis): geração e cogeração na indústria de Óleo de Palma
}

\author{
Palm Energy (Elaeis guineensis): Eletricity Generation and Cogeneration
}

Marcos Alexandre Teixeira(*)

\section{Resumo}

Produzir Óleo de Palma / Dendê (Elaeis guineensis) gera resíduos com potencial energético, os quais podem ser utilizados em regime de cogeração para atender as demandas internas de energia da planta de processamento. Este aproveitamento pode ser otimizado de forma a gerar um superávit de energia elétrica -que pode ser vendido à rede. Neste artigo, buscou-se avaliar as experiências de cogeração associada a plantas de extração de óleo de Palma, no sentido de determinar melhores práticas, assim como avaliar limites para inserção desta tecnologia no Brasil. Para uma unidade típica (60 t cachos de frutos frescos $\mathrm{h}^{-1}$ ), foram estimadas quantidade e custos da energia produzida assim como emissões, em 5 configurações: cenário base (caldeira c/parte das fibras e cascas, vapor saturado e turbina de contra-pressão); cogeração básica (caldeira c/parte das fibras e cascas, vapor saturado e turbina de extração-condensação); cogeração otimizada (caldeira c/fibras, cascas e parte dos cachos de frutas vazios; vapor superaquecido e turbina de extração-condensação); cogeração otimizada com biodigestor para efluentes líquidos e flare; cogeração otimizada e biodigestor com moto geradores (sem flare) e maximização energética (2 caldeiras: p/cachos de frutas vazios e outra p/fibras e cascas, vapor superaquecido e turbina de condensação e moto geradores). Resultados indicam TIR de 7 e $2 \%$, para $\mathrm{R} \$ 80 \mathrm{MWh}^{-1}$. Nos cenários cogeração básica e otimizada, o VPL baixo sugere a necessidade de incentivo à geração de eletricidade, exceto para os cenários denominados: cogeração otimizada e - cogeração otimizada -e biodigestor e moto geradores. A venda de créditos de carbono não teve impacto na performance econômico financeira.

Palavras- Chave: dendê, cogeração, geração de eletricidade, créditos de carbono.

1 Dr.; Engenharia Mecânica; Universidade Estadual de Campinas, UNICAMP, Brasil; Professor das disciplinas de Energização Rural, Alternativas Energéticas e Modelagem de Sistemas Agrícolas e Ambientais, já tendo ministrando Construções Rurais e Instalações Prediais Aplicadas; Endereço: Universidade Federal Fluminense, Centro Tecnológico, Escola de Engenharia. Rua Passo da Pátria 156 Bloco D sala 235, São Domingos. 24210240 - Niterói, RJ - Brasil; E-mail: marcosateixeira@uol.com.br/marcos_teixeira@id.uff.br $\quad\left(^{*}\right)$ Autor para correspondências

\begin{tabular}{llllll}
\hline Ambiência & Guarapuava (PR) v.I5 n.I & p. $257-278$ & Jan/Abr 20I9 & ISSN I808 - 025I
\end{tabular}




\section{Abstract}

Palm oil industries (Elaeis guineensis), produces residues with energy content that can be used with a cogeneration system to support the unit's energy demands. This system can be optimized to maximize the electricity surplus that can be sold to the grid. In this article, several Palm Oil cogeneration experiences were analyzed to identify best practices, as well as to evaluate the limits to its implementation within Brazilian framework. For a typical unit ( $60 \mathrm{t}$ fresh bunch of fruits $\mathrm{h}^{-1}$ ) energy generated and its costs were evaluated as well as emissions. Were considered 5 configurations: base case (boiler with part of fibers and shells, saturated steam back-pressure turbine); basic cogeneration (same feed, saturated steam extraction-condensation turbine); optimized cogeneration (all fibers, shells an part of empty fruit bunches, superheated steam extraction-condensation turbine); optimized cogeneration adding a biodigester for the liquid effluents and methane send to flare, optimized cogeneration with biodigester and internal combustion engines (instead of flare) and, energy maximization (one boiler for the empty fruit bunches, other for fibers and shells, superheated steam extraction-condensation turbine and biodigester feeding internal combustion engines). Based on $80 \mathrm{R} \$ \mathrm{MWh}^{-1}$, IRT were of 7 to $2 \%$ for basic and optimized cogeneration respectively. Low NPV indicates need for specific policy incentive to get this business a reality. Except for the optimized cogeneration and optimized cogeneration with biodigester and internal combustion engines. Carbon credits had no economical or financial impacts.

Keywords: Palm Oil, cogeneration, energy generation, carbon credits.

\section{INTRODUÇÃO}

A cultura de Dendê (em Inglês: Palm Oil), que já era hegemônica na indústria de óleo comestível mundial, com a consolidação dos mercados para o biodiesel, ganhou ainda mais escala e importância, muito em virtude do seu elevado rendimento por hectare.

No momento em que se introduziu o Biodiesel no mercado nacional e internacional, tornando premente o desenvolvimento de novas fontes de óleos para suprir esta nova indústria, se estabelece a necessidade de novo diálogo entre indústria e sociedade, levando em conta as lições aprendidas com o Proálcool; diálogo este necessário para a formulação de um novo horizonte para a indústria nacional de óleo de Dendê. Dentre as recentes consolidações do setor sucro-alcooleiro, tem-se a definição de empresa energética com base em biomassa; onde a cana é um insumo e energia - nas suas mais diversas formas - é o objetivo que passa a ser objeto de otimização.

Esta visão, passa pela valoração da biomassa, não só como fonte de matéria prima, mas como um recurso, em cuja valorização atua uma série de determinantes tecnológicos que influenciam no direcionamento do agronegócio. $\mathrm{Na}$ maioria das vezes, este direcionamento - quando bem entendido pela sociedade - é traduzido em instrumentos de política pública e seus mecanismos, a exemplo de linhas de financiamento disponibilizadas por bancos governamentais, de forma a refletir a política de expansão do setor.

Partindo-se do entendimento dado por SHIKIDA e PEROSA (2012), de que o desenvolvimento de um sistema econômico institucional obedece a uma relação de path dependence, é necessário reconhecer as opções e delimitar quais as escolhas - como sociedade - sejam mais 
interessantes de serem buscadas, ao invés de deixar ao mercado a sua definição, como uma forma de poder dar um direcionamento ao desenvolvimento alinhado com os interesses da sociedade onde este sistema econômico se insere.

Dessa forma, é necessário identificar as bases técnicas que permitam determinar as opções e rotas mais interessantes a serem tomadas pelo setor de produção de óleo de Palma / Dendê, em associação com a produção do Biodiesel, de forma a instrumentar a sociedade e o poder público no sentido de fazer suas opções de forma consciente e em bases sólidas.

Se uma das vertentes observadas na cana de açúcar, já à época do início do Proálcool, é defender a valorização dos seus subprodutos (CORTEZ, et al., 1992), é interessante ter-se o mesmo tipo de abordagem para a indústria de óleo de Palma / Dendê, no que se objetiva a maximização da produção da eletricidade em bases tecnologicamente e economicamente sustentáveis.

Esta valorização energética deve levar à reflexos na diminuição dos impactos ambientais causados pelas unidades industriais; ambas necessitando de instrumentos que suportem a-elaboração de regulamentação específica, que dê amparo a este setor produtivo alinhado aos interesses da sociedade e sustentado por políticas públicas (TONIN, 2014). Atualmente, para o setor de produção do óleo de Dendê / Palma, o uso energético dos resíduos se concentra nas fibras e na casca (desconsiderando o cacho de frutas vazio, por exemplo), cuja queima em caldeiras de 20 bar (vapor saturado) leva à autossuficiência energética da unidade de extração de óleo (demandas de calor e eletricidade).

A maioria dos sistemas utilizados no passado faziam uso de turbinas de contrapressão. Um exemplo da possibilidade de valorização do conteúdo energético dos resíduos seria com a mesma caldeira, mas operando com turbina de extração-condensação poderia aumentar em até $60 \%$ a produção de eletricidade.

Em função de programas governamentais e incentivos do mercado internacional, há uma tendência de utilização dos cachos vazios para geração de eletricidade (em alguns casos como uma unidade separada de negócios). Algumas das unidades operam com vapor superaquecido em pressão de 20 a 40 bar, de 200 a $400{ }^{\circ} \mathrm{C}$.

Um aspecto mais integrado na valorização energética passa por reestruturação da unidade e de suas operações, a exemplo da instalação de mais um conjunto caldeira-turbina, na unidade de cogeração, de forma a poder absorver o superávit de vapor gerado pela biomassa durante safra e pico de safra para geração de excedentes de eletricidade (57 a 113\% de variação do fator de capacidade).

Para o uso dos cachos de frutos vazios, é necessário seu pré-tratamento (triturar e secar), ou co-combustão com outros resíduos (fibras e/ou outra biomassa), em especial devido à sua alta umidade (para queima direta é necessário reduzir de 60 a 70\% para, no mínimo 40\%) no que já existem fornecedores internacionais de equipamentos e sistemas para o processamento desta biomassa.

$\mathrm{Na}$ Ásia, o governo tem procurado incentivar a valorização dos produtos e a diminuição dos impactos associados à expansão das áreas de Culturas sobre florestas e áreas virgens (AUN, 2010). Uma das forças que tem impulsionado estas mudanças são projetos de MDL - Mecanismo de Desenvolvimento Limpo (CDM - Clean Development Mechanism), que dão maior atratividade econômico-financeira para projetos de cogeração com Cachos Vazios (EFB - Empty Fruit Buches) e plantas de biodigestão dos efluentes líquidos (POME - Palm Oil Mill Effluents) tratados em digestores anaeróbios. 
No cenário nacional, é clara a analogia entre o Proálcool e a cadeia do Biodiesel (GARCIA et al., 2007). Dessa forma, este artigo traz uma revisão levantando as experiências de valorização energética associadas ao processamento dos frutos do dendezeiro, como base para a formulação de um cenário em que possa melhor integrar essa nossa biomassa energética- e na matriz energética - nacional.

Como parte dos trabalhos, foram avaliados cinco cenários para aumento da produção de energia elétrica junto a uma unidade típica de processamento de óleo de Dendê, no Brasil, procurando definir: custos de instalação, operação, assim como desempenho econômico-financeiro para as diferentes configurações estudadas.

As características predominantes encontradas no mercado mundial são: uso de turbina de contrapressão, caldeira a 20 bar com Vapor saturado a 20 a $30 \mathrm{t}$ vap. $\mathrm{h}^{-1}$, associada à turbina de contrapressão com extração em 5 a 6,5 bar, com fator de uso ao longo do ano 65\% (HUSAIN et al., 2003); quando do uso de turbinas de extração-condensação, com caldeiras a 20 bar e Vapor super aquecido $\left(270\right.$ a $\left.330{ }^{\circ} \mathrm{C}\right)$ a 10 a $20 \mathrm{t}_{\text {vapor }} \mathrm{h}^{-1}$, podendo levar a potencial de aumento de produção de eletricidade se passada para extração-condensação de 60\% (HUSAIN et al., 2003).

Ainda nesta linha, a auto geração era atingida com queima parcial dos resíduos: $85 \%$ das fibras e 55\% das cascas (KAMAHARA et al., 2010), utilizando-se de um mix nas caldeiras que, em 2000 era $60 \%$ fibras e $40 \%$ cascas), e em 2010 , era de $75 \%$ fibras e $25 \%$ cascas, em especial devido à valorização das cascas e para evitar formação de "fumaça negra", em função da combustão incompleta com o aumento da quantidade de cascas na caldeira (HANSEN et al., 2012).

Em paralelo, segundo ARRIETA et al., (2007), houve uma normalização em termos de unidade típica para a produção do óleo de dendê, com uma área plantada de $100 \mathrm{~km}^{2}$, potência instalada de geração de eletricidade de 5 a 11 MW, operando em Heat to Power: 1 / 17,9; com um potencial de geração de excedentes de eletricidade de $90 \mathrm{a} 132 \mathrm{kWh} \mathrm{t}^{-1}$ cachos de frutos frescos (queimando somente fibras e cascas).

De forma geral, a cogeração tem se estabelecido como uma tecnologia consolidada, porém ainda sem parâmetros definidos, como uma resposta à necessidade de pré-tratamento dos cachos vazios (aumento da demanda de vapor), assim como uma resposta às crescentes dificuldades em gerenciar este resíduo (custo de transporte e problemas na área agrícola).

Segundo ARRIETA et al. (2007) , há uma grande variabilidade com relação à quantidade de excedentes de energia elétrica que podem ser produzidos, a exemplo de unidade na Colômbia, com uma cogeração padrão $(20$ bar) temos um potencial de geração de excedente de energia elétrica de $20 \mathrm{kWh} \mathrm{t}^{-1}$ cachos de frutos frescos; e, passando para turbina extração-condensação, usando $60 \%$ dos cachos de frutos vazios, vapor a 20 bar $350{ }^{\circ} \mathrm{C}$, valores de $75 \mathrm{a}-160 \mathrm{kWh} \mathrm{t}{ }^{-1}$ cachos de frutos frescos (respectivamente, safra e fora da safra).

Dada a flutuação no preço do Óleo de Palma / Dendê Cru (CPO - Crude Palm Oil, ou ODC - Óleo de Dendê Cru), as grandes unidades estão buscando a verticalização para poderem garantir custos competitivos para o biodiesel produzido. A África - região de origem da planta de Dendê - tem entrado no mercado de forma crescente, com unidades verticalizadas, já focadas no mercado de biodiesel, como colocado por Garcia-Nunez et. al. (2016), Yasin et. al. (2017) e Khatun et. al. (2017). 


\section{Material e Métodos}

Este artigo fez uso de um extenso trabalho de revisão bibliográfica de artigos, relatórios e trabalhos de avaliação de diferentes sistemas de cogeração associados à plantas de Óleo de Dendê (Palm Oil), assim como artigos relacionados à cogeração (mesmo que não associada à indústria de óleo). Foram avaliadas as condicionantes de mercado, tanto no lado biodiesel (relacionado à produção do óleo-, quando no do mercado de energia elétrica. Sempre que aplicável, a grafia em português foi acompanhada pela sua congênere em Inglês de forma a estabelecer um glossário de referência.

Para a análise de aderência das tecnologias identificadas e avaliação da atratividade econômico financeira, foi adotada uma unidade padrão de processamento de óleo de Palma de $60 \mathrm{t} \mathrm{cachos} \mathrm{de} \mathrm{frutos} \mathrm{frescos} \mathrm{hora}^{-1}\left(\mathrm{CFF}\right.$ hora $\left.^{-1}\right)$, tamanho limitado pelas operações de transporte dos cachos das áreas de produção para a planta, com análise do potencial sendo considerados os seguintes cenários:

Cenário Base - caldeira queimando parte das fibras e das cascas; poder calorífico médio 14,25 MJ kg-1, gerando vapor saturado a 20 bar, passando por uma turbina de contrapressão, alimentando o processo a 4 bar, sem geração de excedentes de eletricidade, $65 \%$ de fator de utilização da planta, POME tratados em lagoas de estabilização (aberta) e cachos transportados de volta para o campo para decomporem (HUSAIN et al., 2003), como pode ser visto na Figura 1;

Cogeração Básica - caldeira queimando 60\% das fibras e 55\% das cascas, gerando vapor saturado a 20 bar direcionado à turbina de extração condensação, 65\% de fator de utilização da planta, POME tratados em lagoas de estabilização (ARRIETA et al., 2007), como pode ser visto na Figura 2;

Cogeração Otimizada - caldeira queimando fibras, cascas e 60\% dos cachos vazios, gerando vapor superaquecido a $20 \mathrm{bar}, 350^{\circ} \mathrm{C}$, uso de turbina de extração condensação, $65 \%$ de fator de utilização da planta (ARRIETA et al., 2007), como pode ser visto na Figura 3;

Cogeração Otimizada + Tratamento POME - caldeira queimando fibras, cascas e $60 \%$ dos cachos vazios, gerando vapor superaquecido a 20 bar, $350{ }^{\circ} \mathrm{C}$, turbina de extração-condensação, POME tratado em biodigestores, com metano queimado em Flare (ARRIETA et al., 2007), como pode ser visto na Figura 4;

Cogeração Otimizada + Tratamento POME + Gerador Biogás - caldeira queimando fibras, cascas e $60 \%$ dos cachos vazios, gerando vapor superaquecido a $20 \mathrm{bar}, 350{ }^{\circ} \mathrm{C}$, turbina de extração-condensação, POME tratado em biodigestores (ARRIETA et al., 2007), com metano queimado em motores de combustão interna, como pode ser visto na Figura 5; e

Maximização energética - duas caldeiras: uma queimando os cachos vazios (préprocessamento: trituração e secagem) para geração de vapor saturado a 4 bar, para alimentar o processo; e outra queimando $100 \%$ das fibras e $100 \%$ das cascas, gerando vapor superaquecido a 71 bar gerando eletricidade em turbina de condensação (10 MW). POME tratado em biodigestores e metano gerado alimentando motores de combustão interna para gerar eletricidade (0,6 MW) (IRG, 2011), como representado na Figura 6. 
Figura 1 - Representação simplificada do Cenário Base.

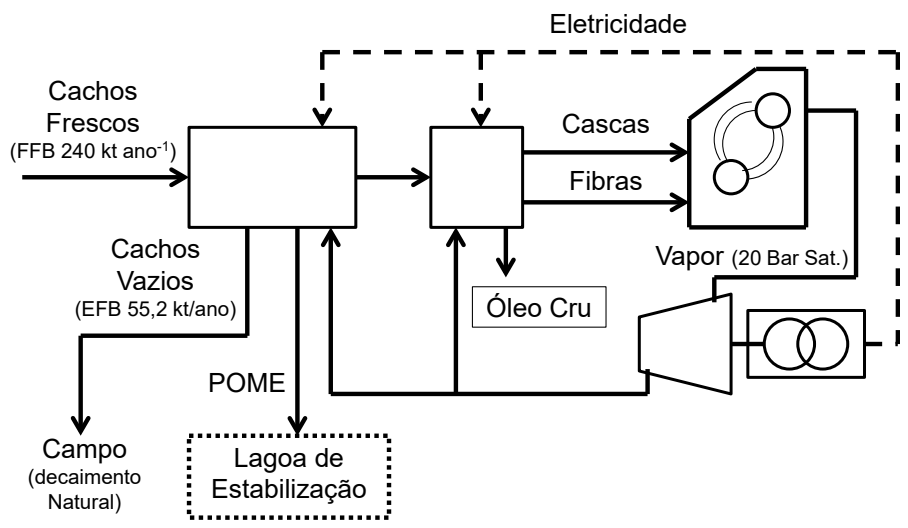

Figura 2 - Representação simplificada do Cenário Cogeração Básica.

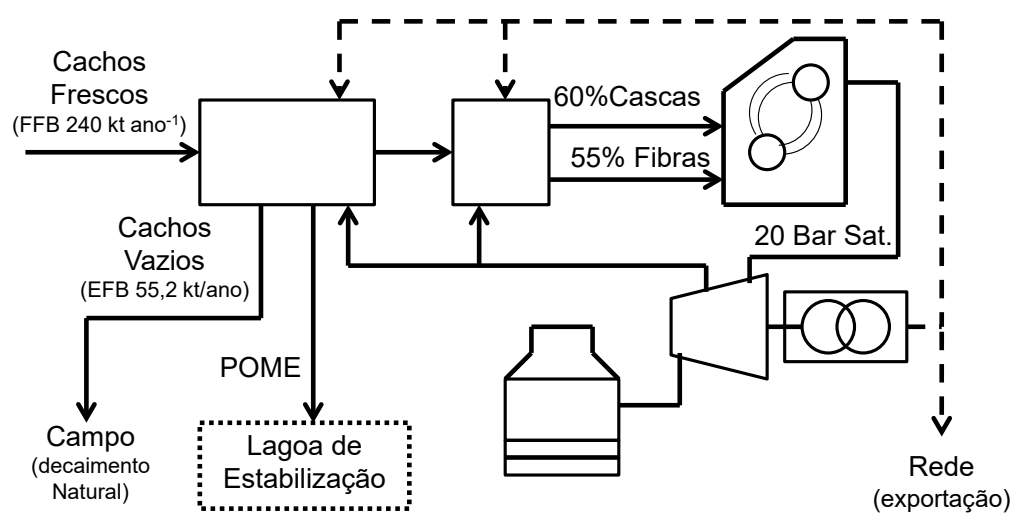

Figura 3 - Representação simplificada do cenário Cogeração Otimizada.

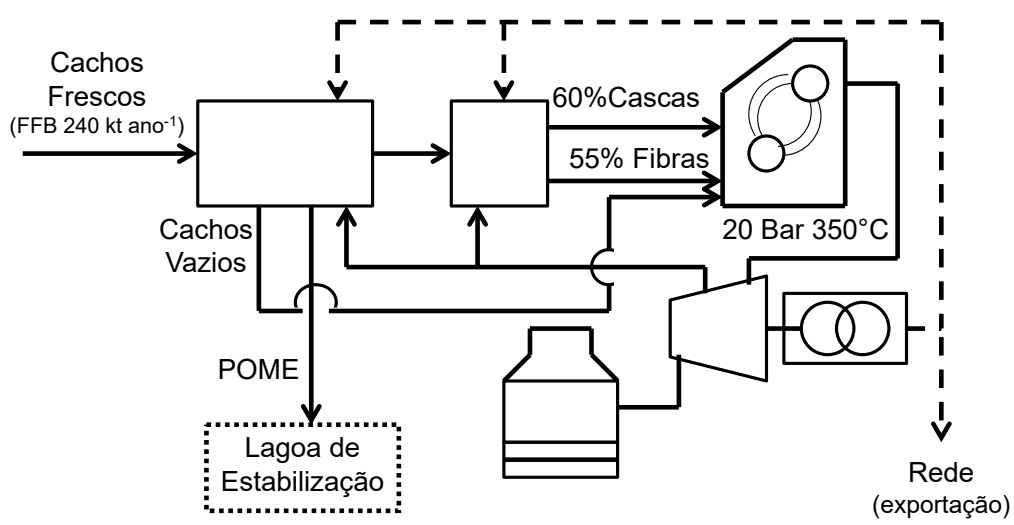


Figura 4 - Representação simplificada do cenário Cogeração Otimizada com Tratamento POME.

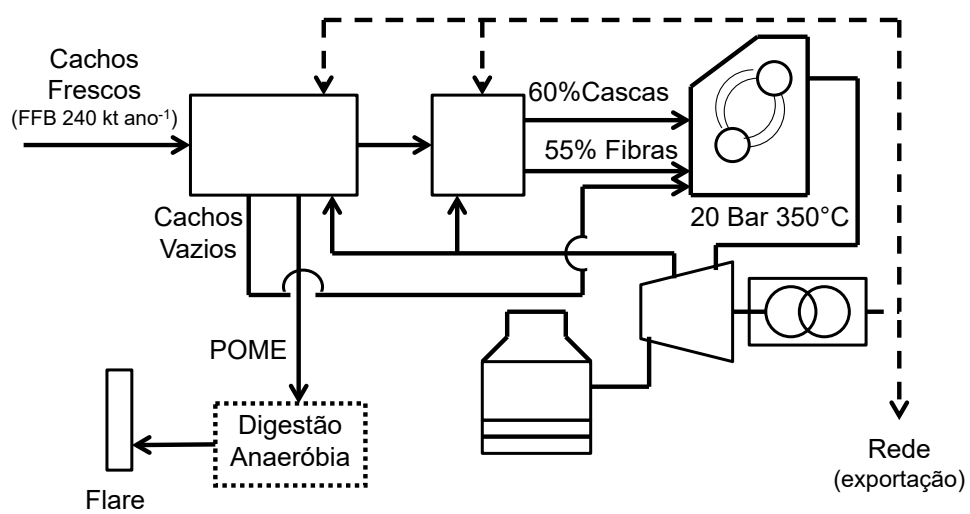

Figura 5 - Representação simplificada do cenário Cogeração Otimizada + Tratamento POME + Gerador Biogás.

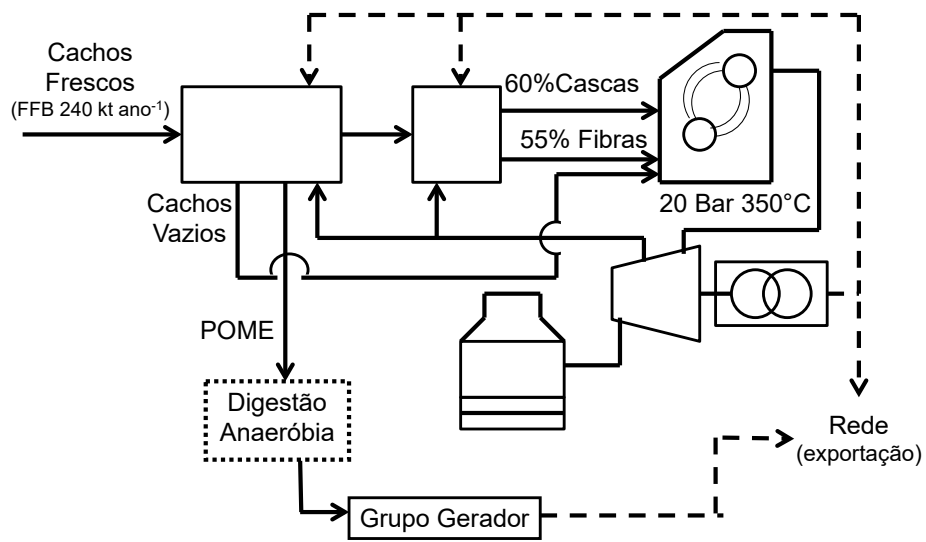

Figura 6 - Representação simplificada do cenário Maximização Energética.

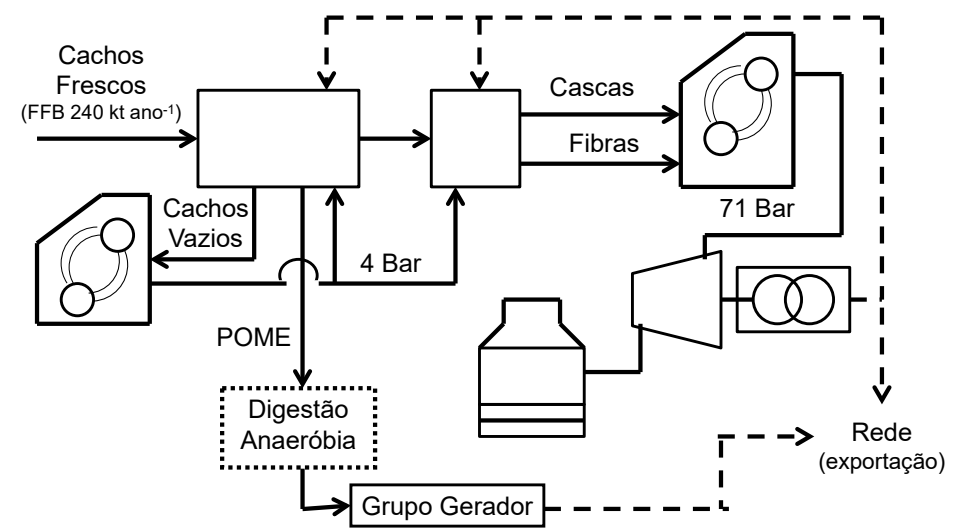

Para estimar as emissões evitadas com a eletricidade injetada na rede, foram consultados os dados disponibilizados pelo MCT - Ministério da Ciência e Tecnologia para o cálculo da margem combinada, adotando os valores para o SIN, no valor de 0,2499 t $\mathrm{CO}_{2 \text { equivalente }} \mathrm{MWh}^{-1}$ (MCTI, 2013). Estes cálculos se baseiam na metodologia emitida pela UNFCC - United Nations Framework Convention on Climate Change, denominada "Tool to calculate the emission factor for an electricity system”, na sua versão 4.0 e seus anexos (UNFCCC, 2010). Os cálculos com base nesta 
metodologia são disponibilizados pelo Ministério de Ciência e Tecnologia, como parte de suas atribuições como Autoridade Nacional Designada -AND (NDA - National Designated Authority).

Para a estimativa de viabilidade dos cenários, foram utilizados os seguintes valores: cotação Dólar R \$ 2,00 US\$ $\$$, cotação Euro R $\$ 2,6$ Euro $^{-1}$ e valor para a eletricidade vendida / produzida em R\$ $80 \mathrm{MWh}^{-1}$.

Para a determinação do valor a ser pago pela eletricidade, foram tomados como base, os valores do PLD (Preço de Liquidação das Diferenças), à época do estudo (início de 2012, quando o mercado já sinalizava uma tendência de subida nos preços), calculados pela CCEE - Câmara de Comercialização de Energia Elétrica.

O PDL é utilizado para valorar a energia comercializada no mercado de curto prazo, levando em consideração: as condições hidrológicas, demanda de energia, preços de combustível, disponibilidade de equipamentos de geração e transmissão, determinação do despacho entre as diversas fontes geradoras (ex.: hidráulica ou térmica) pelo ONS - Operador Nacional do Sistema, entre outras entidades. Seu cálculo é normalizado pelo Conselho Nacional de Política Energética - CNPE e tem os valores máximos e mínimos limitados pela ANEEL (CCEE, 2014).

Este indicador é dividido entre os sub mercados SE/CO, S, NE e N, e são utilizados pelo setor privado como um indicativo de tendência do mercado no curto prazo, uma vez que é sensível à maioria dos fatores de produção. Na Figura 9, a evolução dos valores médios do PDL de 2003 a 2014, evidenciando sua volatilidade e resposta aos custos associados ao mercado de produção de energia elétrica.

É prática comum no mercado privado utilizar os valores emitidos pela CCEE e, com base em índices próprios do seu setor (ex. inflação esperada, crescimento do mercado, percentual de auto geração de energia, etc), fazer uma projeção do custo da energia elétrica para auxiliar o processo de tomada de decisão.

\section{Figura 7 - Evolução do PDL - Peço de Liquidação das Diferenças.}

Evolução do PDL - Preço de Liquidação das Diferenças (média regiões SE/CO, S, NE e S)
Emitido pela CCEE - Câmara de Comercialização de Energia Elétrica

Fonte: http://www.ccee.org.br/

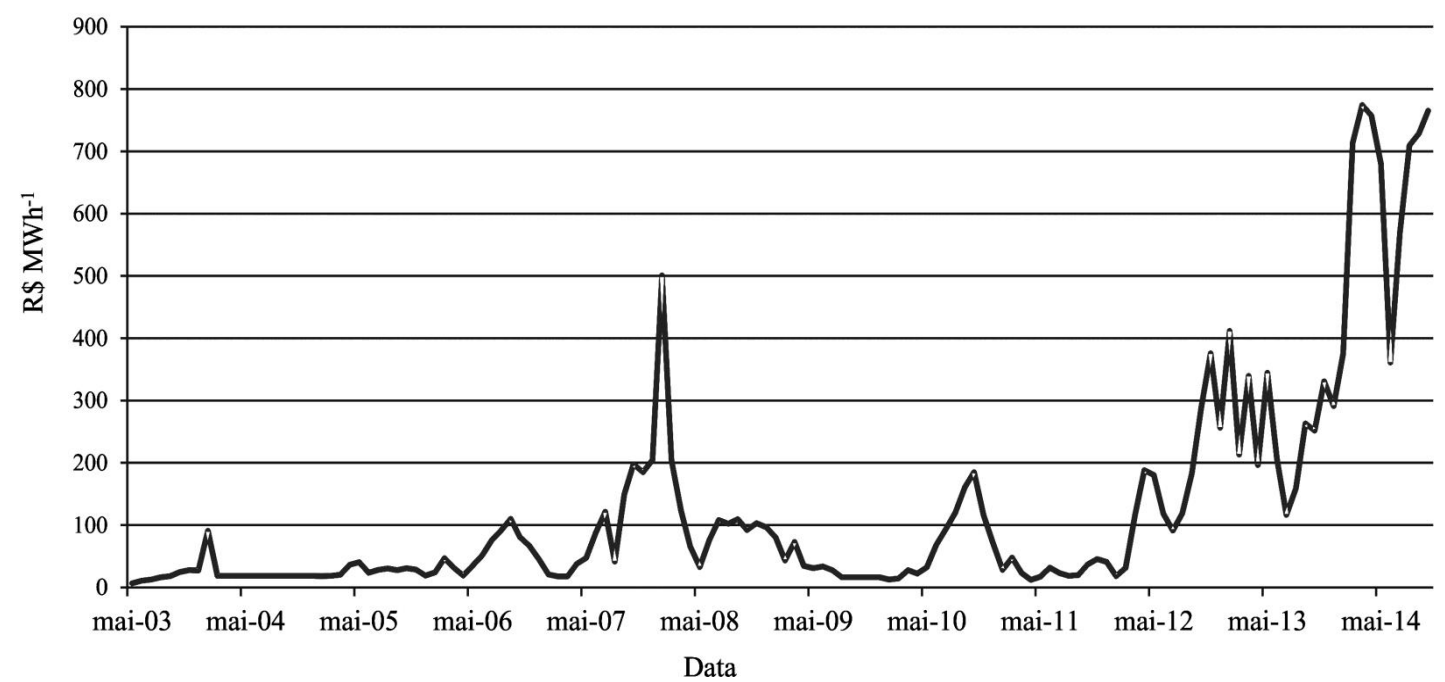

(Fonte: CCEE, 2014). 
Para os custos dos ciclos a vapor, foram adotados: 3.619 k US $\$ \mathrm{MW}^{-1}$ e $161 \mathrm{k}$ US\$ $\mathrm{MW}^{-1}$ ano para o ciclo a vapor operando com turbina de extração-condensação e $2.840 \mathrm{k} U S \$ \mathrm{MW}^{-1} \mathrm{e}$ 105 k US\$ MW ano para a turbina de contrapressão (TEIXEIRA et al., 2013).

Para a combustão dos cachos de frutas vazios (EFB), gerando vapor, segundo configuração descrita por IRG (2011), - levando a valores de US $\$ 141,7$ para cada tonelada de cachos de frutos frescos, em termos de capacidade instalada, com $3 \%$ ao ano para custos operacionais.

Para o biodigestor, foi feita consulta direta à empresa Sansuy (a menção de marcas não constitui recomendação por parte do autor), indicando $R \$ 827,81$ por cada $\mathrm{m}^{3} \mathrm{dia}^{-1}$ de capacidade instalada para produção de metano.

Os custos de manutenção de um sistema anaeróbio assim como a instalação do fare fechado (capacidade de $4.500 \mathrm{~m}^{3} \mathrm{dia}^{-1}$ ) foram adotados do DCP (Documento de Concepção de Projeto) da usina São Roque (cidade de Videira/ SC), com flare fechado, orçado a $\mathrm{R} \$ 75.517,00$, manutenção dos sistemas a $\mathrm{R} \$ 30.190,49$ ano $^{-1}$ e sistema de medição do Gás a $\mathrm{R} \$ 131.600,00$ (PROENÇA, 2009). Eficiência de destruição do metano de 90\%, adotou-se a densidade do metano como constante a $0,676 \mathrm{~kg} \mathrm{~m}^{-3}$ (PROENÇA, 2009).

Para o custo de instalação e operação do grupo gerador operando a biogás, foram adotados os valores de $\mathrm{R} \$ 1.055 .500 \mathrm{MW}^{-1}$ de investimento e $\mathrm{R} \$ 500.000$ ano $^{-1}$ de operação e manutenção, e eficiência do sistema de captura do metano e direcionamento para os grupos geradores de $97 \%$ de eficiência (SILVA et al., 2009).

Para os custos de elaboração de projeto de redução, submissão e manutenção dos projetos de redução de emissões adotados para mercado regulado foram: 100.000 Euro Projeto ${ }^{-1}$ e 30.000 Euro $a_{n o}^{-1}$ e, para o mercado voluntário: $\mathrm{R} \$ 260.000$ Projeto $^{-1}$ e $\mathrm{R} \$ 78.000$ ano $^{-1}$. Para o valor de venda das emissões reduzidas foram adotados: 1 Euro $\mathrm{T} \mathrm{CO}_{2 \text { equiv. }}{ }^{-1}$ mercado regulado e US\$ $3 \mathrm{TCO}_{2}$ equivalente ${ }^{-1}$ mercado voluntário (KELLEY e GALLANT, 2017).

Para a análise financeira, foi considerado a Taxa Interna de Retorno Simples (TIR) e Valor Presente Líquido (VPL), com uma taxa de remuneração de capital de $10 \%$ ao ano, projeto com vida útil de 25 anos, com 4000 horas trabalhadas durante o ano, considerando-se a venda de eletricidade e dos créditos de carbono - no mercado voluntário e no mercado de MDL, como fontes de renda (dado que o ganho com a venda de óleo de Dendê é equivalente para todos os cenários).

\section{RESULTADOS E DISCUSSÃO}

Na Tailândia e Malásia, a cultura do Dendê veio como um substituto à cultura da Borracha, e fazia uso de combustíveis fósseis e lenha nas caldeiras. Iniciando seu ciclo de expansão entre os anos de 1960 até 2000, as unidades produtoras se caracterizavam por pequenas capacidades. Atualmente as unidades vão de 10 até $60 \mathrm{t}$ cachos de frutos frescos (CFF) hora ${ }^{-1}$. (MAHLIA et al. 2001). Na Indonésia, quando introduzida como uma nova cultura (Green Field) é bastante criticada por devastação da floresta tropical.

Para o caso brasileiro, como colocado por PAULILLO et al. (2007), a cadeia do biodiesel depende de um paradigma subvencionista, atrelada ao preço do petróleo e a orquestração de interesses em torno do biodiesel. Neste sentido, é necessário entender os limites de seu aproveitamento energético e opções para a minimização de seus impactos no meio ambiente; dois aspectos que podem nortear fortemente uma possível revisão do Programa Nacional de Produção e Uso de Biodiesel (PNPB). 
Em termos de mercado nacional, uma unidade típica de processamento tem uma capacidade instalada, dada em termos de sua capacidade de processamento de Cachos de Frutos Frescos (FFB - Fresh Fruit Bunches). O tamanho típico são unidades com capacidade instalada de 30 a 60 t CFF h ${ }^{-1}$, cujo esquema típico de cogeração pode ser visto na Figura 8, gerando 6,61 kWh $\mathrm{t}^{-1}$ cachos frescos de eletricidade e 24,2 $\mathrm{MJ} \mathrm{t}^{-1}$ cachos frescos de vapor. Se parte deste excesso de calor for utilizado para secar os cachos vazios, o excesso de calor seria de $105,2 \mathrm{MJ} \mathrm{t}^{-1} \mathrm{CFF}$ (CHIEW et al., 2011).

No mesmo trabalho, foi sugerido que os melhores ganhos se dão com duas plantas de cogeração, 1,2 e $6 \mathrm{MW}$, de forma a poder ter flexibilidade durante o período de safra e de pico de safra (CHIEW et al., 2011).

\section{Figura 8 - Representação geral do sistema de cogeração para unidade de 30 a 60 t cachos de frutos frescos $h^{-1}$.}

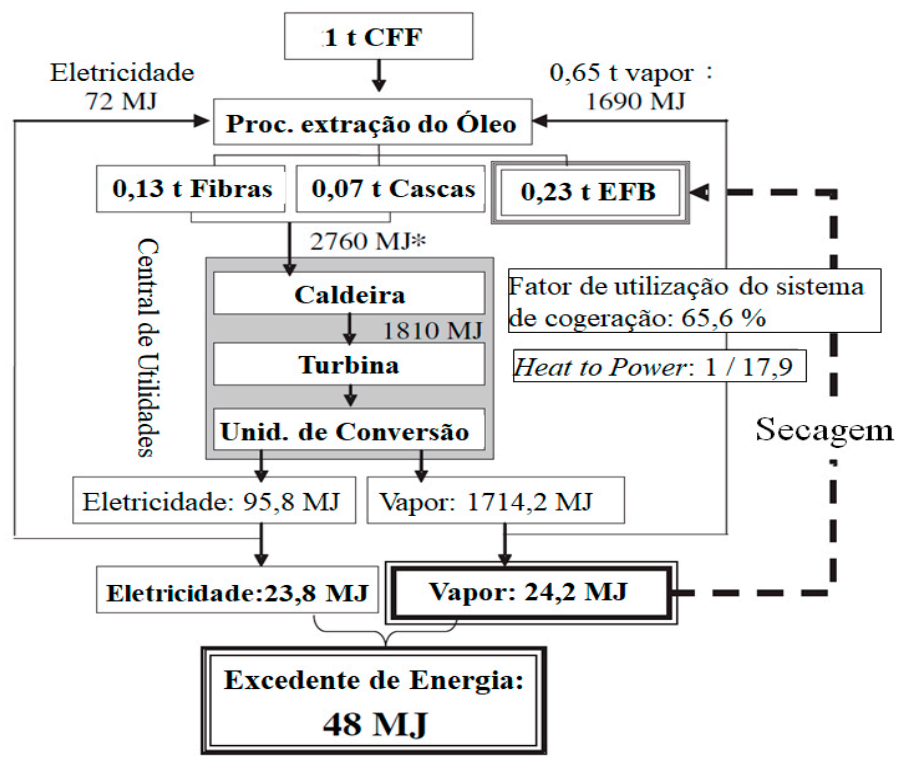

(Fonte: CHIEW et al., 2011)

O processo de extração de Óleo de Dendê envolve a extração mecânica do óleo do mesocarpo e do endocarpo do fruto (prensagem), para obter maiores rendimentos (\% do óleo removido), é necessário o aquecimento (com uso de vapor de baixa pressão), tanto dos cachos de frutos frescos, quanto do Palmiste (amêndoa no interior do fruto - Kernel). Desta forma, as demandas energéticas se concentram em potência para os motores (prensagem), e calor para algumas etapas do processo (vapor para aquecimento), a saber:

Vapor para esterilização dos cachos $-140{ }^{\circ} \mathrm{C}$ (50 a 75 minutos a 3 bar $)$ - importante para parar os processos biológicos que degradam o óleo e facilitar a separação dos frutos do cacho. Gera um condensado que é um dos principais efluentes do processo; e

Água quente na separação emulsão óleo água - 80 a $90^{\circ} \mathrm{C}$ - para facilitar a separação entre a torta e o óleo.

Abaixo, alguns dos parâmetros considerados para a operação de uma planta de extração de óleo de dendê:

Extraction Rate - $188 \mathrm{~kg}$ óleo $\mathrm{t}^{-1}$ cachos de frutos frescos (HUSAIN et al., 2003).

Heat to Power Rate - 1 / 17,9 (HUSAIN et al., 2003)

Consumo de Vapor - $28 \mathrm{~kg} \mathrm{kWh} \mathrm{kW}^{-1} 3$ a 4 bar de vapor saturado (HUSAIN et al., 2003) 
Consumo de eletricidade:

$30,2 \mathrm{kWh} \mathrm{t}^{-1}$ cachos de frutos frescos (HUSAIN et al., 2003)

$20 \mathrm{kWh} \mathrm{t}^{-1}$ cachos de frutos frescos (MAHLIA et al. 2001)

17 a $38 \mathrm{kWh} \mathrm{t}^{-1}$ cachos de frutos frescos - Malásia (ARRIETA et al., 2007)

20 a $25 \mathrm{kWh} \mathrm{t}^{-1}$ cachos de frutos frescos - Tailândia (ARRIETA et al., 2007)

Na Figura 9, tem-se uma representação simplificada do balanço de massa e energia para a planta de extração de óleo de Dendê.

\section{Figura 9 - Balanço de massa e energia para a extração do Óleo de Dendê.}

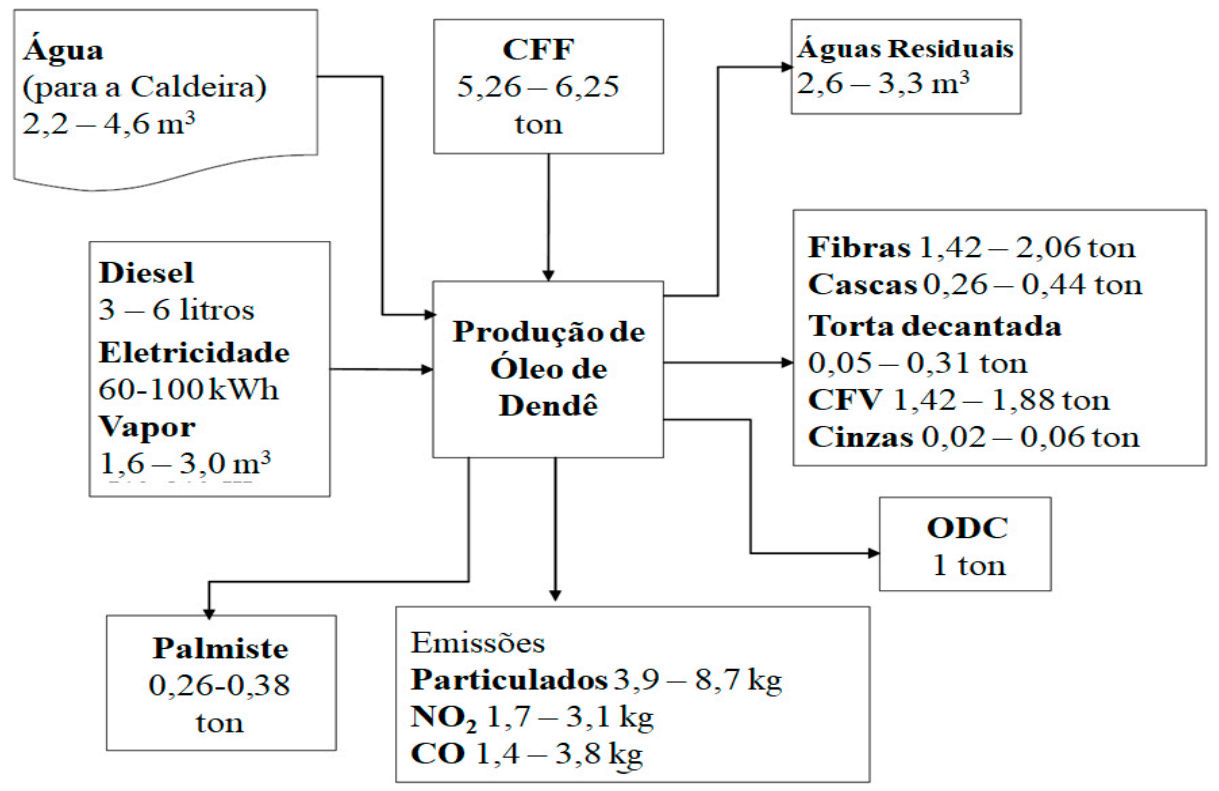

(PLEANJAl et al., 2007)

Abaixo, uma caracterização dos principais resíduos do processamento dos frutos da palmeira de Dendê (ARRIETA et al., 2007):

Cachos vazios (EFB - Empty Fruit Bunches) - umidade até 70\% - 8,16 MJ/kg. Apresentam possibilidade de serem incorporados ao solo para reciclar nutrientes - somente 60\% para queima (dados sugerem que compensa financeiramente a compra do adubo);

Cinzas têm alto percentual de Potássio, sendo fundentes. Segundo (JOO-HWA KUANYEOW, 1995), 5\% são cinzas com pouco valor agrícola, $\mathrm{PH} \mathrm{1;} \mathrm{principais} \mathrm{componentes:} \mathrm{A1}$ $(36,2 \%), \mathrm{K}(24,7 \%)$ e $\mathrm{Si}(21,3 \%)$.

Fibras da polpa (PPF - Palm Press Fibers) - após separação do caroço - 18,6 MJ kg-1. Potencial para outros usos: estabilização solos, matéria prima similar à fibra de coco. Principal combustível, a ser utilizado na caldeira (39\% de umidade);

Casca do caroço interno - 6 a 7\% umidade - 20,8 $\mathrm{MJ} \mathrm{kg}^{-1}$. Potencial de mercado para indústria de cimento e siderúrgica (carbono fixo de aproximadamente 20\%);

Águas residuais do processo - Efluentes (Mistura de 3 fontes - POME Palm Oil Mill Efluent): Condensado do efluente 17\%, Separador / Decantador - 75\%, Hidrociclone - 8\%. Produção total - 0,87 $\mathrm{m}^{3} \mathrm{t}^{-1}$ cachos de frutos frescos - DBO $50 \mathrm{~kg} \mathrm{l}^{-1}$. Destinação padrão: lagoas anaeróbias, opção mais viável: biodigestores anaeróbios $-12 \mathrm{~m}^{3}$ Biogás com $60 \% \mathrm{CH}_{4} \mathrm{~m}^{-3}$ efluente. 
A produção de POME varia em função dos critérios de operação da planta, como no processo de esterilização dos cachos e controle de retorno de condensado. Tendo sido encontrados diversos valores na literatura, $0,256 \mathrm{~m}^{3} \mathrm{t}^{-1}$ Cachos de frutos frescos (PLEANJAI et al., 2007), 0,45 $\mathrm{m}^{3} \mathrm{t}^{-1}$ cachos de frutos frescos (IRG, 2011) a $0,87 \mathrm{~m}^{3} \mathrm{t}^{-1}$ cachos de frutos frescos (ARRIETA et al., 2007). Para este trabalho, foi adotado um valor de $0,6 \mathrm{~m}^{3} \mathrm{t}^{-1}$ cachos de frutos frescos para o Cenário Base e 0,45 para os demais.

Com relação às emissões resultantes do tratamento anaeróbio da linha de base (lagoas anaeróbias e facultativas), as variações encontradas na literatura se dão pela diferença no tempo de retenção hidráulica e na DQO removida do efluente. Em discussão sobre os diferentes métodos e suas eficácias MAN KEAT (2011), citando os dados recomendados pelo IPCC indica: 0,6 $\mathrm{m}^{3}$ POME $\mathrm{t}^{-1}$ cachos de frutos frescos, eficiência de remoção da DQO de $85 \%$ com eficiência máxima de produção de metano de $0,25 \mathrm{~kg} \mathrm{CH} 4 \mathrm{~kg}^{-1}$ DQO, DQO degradável de $51 \mathrm{~kg} \mathrm{~m}^{-3}$ POME, entre outras considerações como descrito na metodologia AMS-III.H Revisão número 16 da metodologia pela UNFCCC (2010). Para este trabalho foi adotado, de forma conservativa, um valor de $0,45 \mathrm{~m}^{3}$ de POME t-1 cachos de frutos frescos (IRG 2011), levando a uma produção de $0,00463 \mathrm{~kg} \mathrm{CH}_{4} \mathrm{t}^{-1}$ cachos de frutos frescos, valores adotados para os cenários com somente lagoas de estabilização (sem biodigestor).

Para o sistema de tratamento, biodigestor de lona, há um aumento na produção de metano, correspondendo a um valor de $12,36 \mathrm{~kg} \mathrm{CH}_{4} \mathrm{t}^{-1} \mathrm{POME}$, com metano à concentração de 54\%, em sistemas de biodigestão, sendo que $12 \mathrm{~kg} \mathrm{CH}_{4} \mathrm{t}^{-1} \mathrm{POME}$ são captados. Para a conversão do biogás em eletricidade, adotou-se 0,215 $\mathrm{MWh} \mathrm{t}^{-1} \mathrm{CPO}$ ou 0,061 $\mathrm{MWh} \mathrm{t}^{-1} \mathrm{POME}$ (HANSEN et al., 2012).

Para o cômputo da relação entre energia fóssil consumida para a produção do óleo de Dendê e energia renovável disponibilizada, foram utilizados os dados de QUEIROZ (2012), adotando-se o óleo com $9104 \mathrm{kcal} \mathrm{kg}^{-1}$, e o consumo de energia fóssil de $659 \mathrm{kcal} \mathrm{kg}^{-1}$ de CPO, estabelecendo uma relação de 13,8 entre energia renovável e fóssil.

A dimensão típica do digestor anaeróbio, para um tempo de retenção de 20 dias, foi dada por 20,24 $\mathrm{m}^{3}$ de reator por $\mathrm{m}^{3}$ POME tratado por dia (SHAHRAKBAH et al., 2005). Para uma lagoa de tratamento anaeróbio, temos $191 \mathrm{~m}^{3} \mathrm{t}^{-1} \mathrm{POME} \mathrm{h}$ e a relação entre os custos de uma lagoa para os de um reator anaeróbio, de 0,2906 (POH CHONG, 2009).

Para as emissões resultantes da degradação dos cachos vazios EFB enviados para aterro, adotou-se valores entre 890 a $1480 \mathrm{~kg} \mathrm{CO}_{2 \text { eqiv. }} \mathrm{t}^{-1} \mathrm{CPO}$, com base no trabalho de HANSEN et al. (2012).

Para os excedentes de geração de eletricidade, com base em queima dos Cachos vazios, em ciclos a vapor, considerando sistemas convencionais de cogeração, adotou-se $20 \mathrm{kWh} \mathrm{t}^{-1}$ cachos de frutos frescos e, para a cogeração otimizada, $75 \mathrm{MWh} \mathrm{t}^{-1}$ cachos de frutos frescos (ARRIETA et al., 2007).

Os resultados de geração de excedentes de energia elétrica, para os cinco cenários considerados, podem ser vistos na Tabela 1 . 


\section{Tabela 1 - Potência total e valores para energia produzida e renda com a venda de excedentes para as cinco configurações.}

\begin{tabular}{cccc} 
Cenário & $\begin{array}{c}\text { Potência Média } \\
{[\mathbf{M W}]}\end{array}$ & $\begin{array}{c}\text { Eletricidade Prod. } \\
{\left[\mathbf{M W h} \mathbf{~ a n o}^{-1}\right]}\end{array}$ & $\begin{array}{c}\text { Venda Eletricidade } \\
{\left[\mathbf{k R} \mathbf{\text { ano }} \mathbf{~ a n d ~}^{-1}\right]}\end{array}$ \\
Cog. Básica & 0,55 & 4.800 & 384 \\
Cog. Otimizada & 2,05 & 18.000 & 1.440 \\
Cog. Otim. + POME & 2,05 & 18.000 & 1.440 \\
Cog. Otim.+ Ger. Gás & 3,23 & 28.320 & 2.265 \\
Max. Energética & 10,0 & 88.020 & 7.082 \\
\hline
\end{tabular}

Como pode ser visto pelos números, há uma grande variação na quantidade de energia elétrica excedente produzida; mas em termos de potência instalada, uma concordância com os valores praticados nos programas dos governos do Sudeste Asiático, que nos anos 90, iniciaram programas para incentivo da geração com biomassa com contratos de compra de energia, limitados a unidades de até 10 MW (MAHLIA et al., 2001) (HUSAIN et al.,2003) (SHUIT et al.,2009), como no caso do cenários Maximização energética.

Esta imposição, em termos de potência instalada, leva a uma regulação indireta nos tamanhos das unidades, restringindo em capacidades instaladas máximas de $60 \mathrm{t}$ cachos de frutos frescos hora ${ }^{-1}$, de forma a não incentivar grandes unidades industriais, levando à uma diluição dos impactos gerados pelas plantas, assim como descentralização na geração de emprego e renda.

Os resultados para o desempenho econômico e financeiro para a geração de excedentes de eletricidade podem ser vistos na Tabela 2.

\section{Tabela 2 - Performance econômica financeira para as cinco configurações.}

\begin{tabular}{|c|c|c|c|c|c|}
\hline Cenário & $\begin{array}{c}\text { CAPEX } \\
{[\mathbf{k U S} \$]}\end{array}$ & $\begin{array}{l}\text { Base Potência } \\
\text { [MUS\$ MW'-1] }\end{array}$ & $\begin{array}{c}\text { OPEX } \\
\text { [US\$ ano- } \\
1]\end{array}$ & $\begin{array}{l}\text { TIR } \\
{[\%]}\end{array}$ & $\begin{array}{c}\text { VPL } \\
\text { [MUS\$] }\end{array}$ \\
\hline Cog. Básica & 1.556 & 2,84 & 58 & 6,90 & $-0,35$ \\
\hline Cog. Otimizada & 7.436 & 3,62 & 331 & 1,91 & $-3,94$ \\
\hline $\begin{array}{l}\text { Cog. Otim. + } \\
\text { POME }\end{array}$ & 9.404 & 4,58 & 402 & $-1,60$ & $-6,55$ \\
\hline $\begin{array}{l}\text { Cog. Otim.+ } \\
\text { Ger. Gás }\end{array}$ & 9.922 & 3,07 & 681 & 0,72 & $-5,87$ \\
\hline Max. Energética & 41.763 & 4,16 & 1.994 & $-1,02$ & $-28,04$ \\
\hline
\end{tabular}

Com base nos números encontrados, pode-se dizer que a geração de excedentes de energia elétrica, dentro do contexto da unidade de processamento de óleo de Dendê, dada as condições de contorno, apresenta viabilidade econômica (paga seus custos com retorno positivo sobre o capital).

Se for observada a tendência mundial de valorização dos resíduos, tem-se os ótimos de valorização energética definidos como (IRG,2011): queima direta das fibras e cascas em caldeiras de 25 bar, associado à cogeração com vapor a 71 bar, operando 7000 hora ano ${ }^{-1}$; queima direta dos frutos vazios em caldeiras de baixa pressão 4 a 6 bar para atender calor de processo a 4 bar, numa vazão de $18 \mathrm{t} \mathrm{h}^{-1}$; e POME enviados para digestão anaeróbia a razão de $90000 \mathrm{~m}^{3}$ ano $\mathrm{o}^{-1}$, gerando $180 \mathrm{~m}^{3}$ ano-1 de metano, que alimenta dois motores de $600 \mathrm{~kW}$, com recuperação de calor para aquecimento de parte da água usada na planta. 
É com surpresa que se tem que, com base nos números encontrado, a viabilidade econômicafinanceira é inversamente proporcional à potência instalada, em que o adicional de potência e, consequentemente, de energia gerada, não são proporcionais ao acréscimo da energia produzida.

Estes números, leva à conclusão - sem que se façam agir fatores de regulamentação e incentivos - de que é mais vantajoso do ponto de vista de valorização do capital, gerar a menor quantidade possível de eletricidade (cenário de Cogeração Básica), o que poderia a não se ter um aproveitamento integral dos recursos oferecidos pela biomassa. Desta forma, para que seja majorada a valorização energética dos subprodutos, é necessário colocar em prática mecanismos que levem o setor produtivo a adotar práticas que não sejam decididas puramente pelo retorno sobre o capital, como no caso Cogeração Básica e Cogeração Otimizada, onde houve um decréscimo de mais de 70\% na TIR (muito em função do aumento nos custos de operação).

Porém, caso sejam impostas práticas de regulamentação no tocante aos resíduos gerados, como no caso da necessidade de tratamento do POME, a geração de eletricidade poderá agregar um aumento na rentabilidade da operação, como no caso do cenário Cogeração Otimizada + POME e o Cogeração Otimizada + Tratamento POME + Gerador Biogás.

Um dos resultados mais significativos, porém, é a predominância total dos valores negativos do Valor Presente Líquido, indicando que a opção pela comercialização de energia elétrica não apresenta uma atratividade econômica significativa para atrair o interesse do capital privado (menor que $10 \%$ ao ano).

Os resultados para os impactos ambientais e balanço entre energia fóssil e renovável podem ser vistos na Tabela 3.

\section{Tabela 3 - Emissões e relação entre combustíveis fósseis e renováveis para as cinco configurações.}

\begin{tabular}{cccccc}
\hline Cenário & Totais & Reduções & $\begin{array}{c}\text { Emissões [T CO } \\
\text { Tratamento } \\
\text { POME }\end{array}$ & $\begin{array}{c}\text { ano-1] } \\
\text { Emitido } \\
\text { EFB }\end{array}$ & $\begin{array}{c}\text { Relação } \\
\text { Renovável - } \\
\text { Fóssil }\end{array}$ \\
\hline Base & 83.058 & - & 23.334 & 59.724 & 13,8 \\
Cog. Básica & 81.859 & 1.200 & 23.334 & 59.724 & 13,9 \\
Cog. Otimizada & 42.725 & 40.333 & 23.334 & 23.890 & 14,3 \\
Cog. Otim. + POME & 21.725 & 61.333 & 2.333 & 23.890 & 14,3 \\
Cog. Otim.+ Ger. Gás & 17.500 & 65.558 & 816 & 23.890 & 14,5 \\
Max. Energética & -21.309 & 104.367 & 816 & 0 & 16,1 \\
\hline
\end{tabular}

No âmbito da melhoria na performance ambiental, o incentivo à cogeração levou à diminuições consistentes nas emissões, assim como apresentaram um aumento da relação entre energia renovável disponibilizada frente à energia fóssil de 3 a 5\% entre os cenários mais favoráveis à 16\% no cenário de Maximização Energética, indicando que o impacto, embora positivo, não chega a ser significativo - ficando o óleo e o respectivo biodiesel com a maior parcela da energia renovável aportada ao sistema (quando este for usado nos motores).

No caso de se buscar um limite de emissões por óleo produzido, ou mesmo procurar impor uma política mandatória de redução das emissões da planta de processamento de Dendê, os resultados sugerem que o foco deverá ser nas atividades que ocorre no sistema de tratamento do POME em lagoa anaeróbia; não só por ser esta uma grande fonte de emissões de metano, mas também por ser muito mais gerenciável que a destinação final dos cachos vazios; 
Uma problemática é que buscar estas reduções levam a um impacto negativo na atratividade (não paga os custos), assim como no caso de se buscar total maximização da energia produzida, devendo então ser imposta (forçando a internalização desta externalidade), ou compensando por meio de benefícios.

A adoção conjunta das tecnologias mencionadas ao longo do trabalho reflete uma visão de valorização energética de resíduos, contra a visão de uma cultura energética como no caso da cana de açúcar, ou seja, a escolha da tecnologia é determinante na lucratividade, sendo que as melhores tecnologias (melhor rendimento energético), não levam às melhores performances econômicas, assim, que o preço de venda da eletricidade é um fator chave no processo de tomada de decisão.

Frente aos resultados encontrados, foi realizada análise de sensibilidade para analisar o comportamento da TIR frente à elevação do preço da eletricidade, como pode ser visto na Figura 10 .

\section{Figura 10 - Análise de sensibilidade da TIR para diferentes valores de eletricidade vendida.}

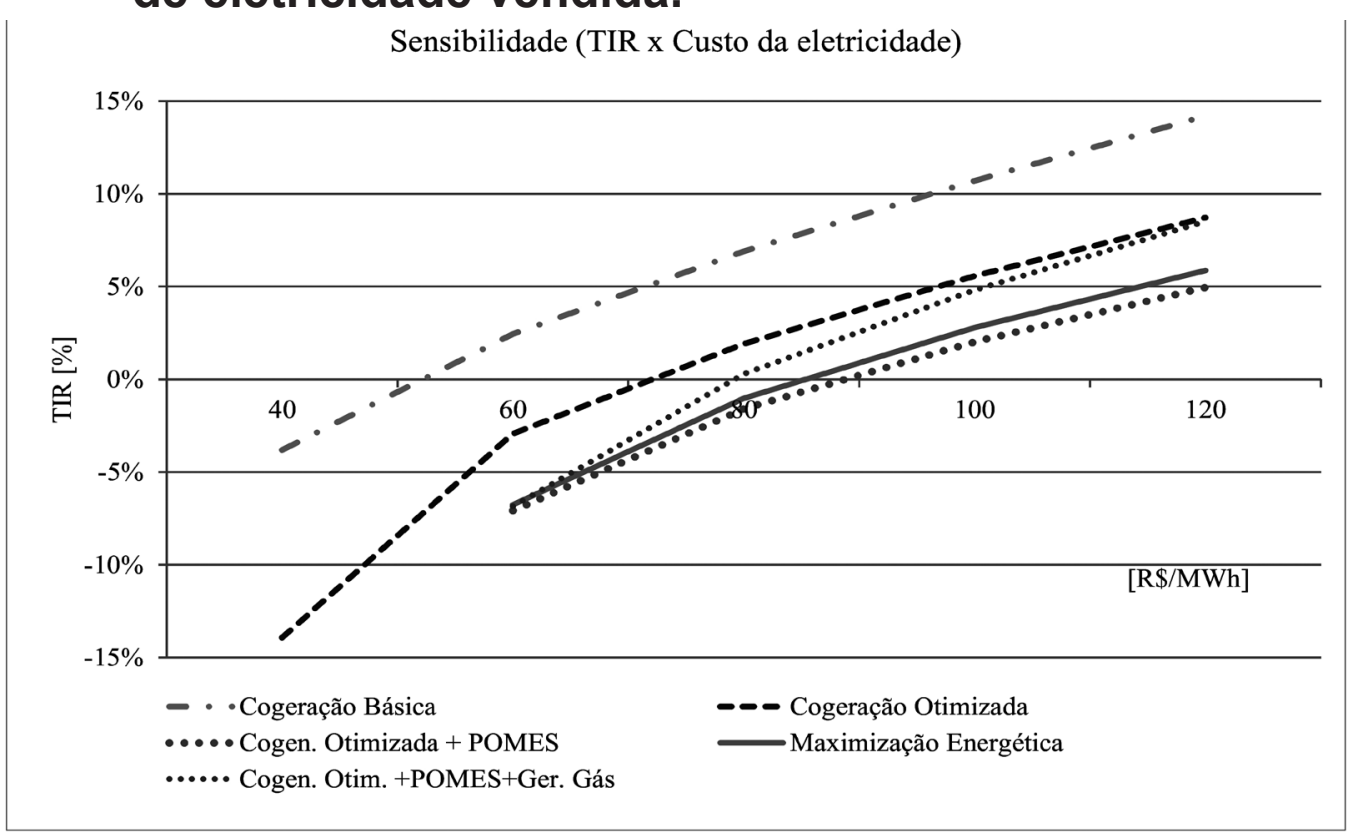

Conforme pode ser visto, os valores mínimos são da ordem de $\mathrm{R} \$ 51 \mathrm{MWh}^{-1}$ para o cenário Cogeração Básica, R $\$ 70$ para cogeração Otimizada, R $\$ 88$ com o tratamento de POME. A Maximização Energética necessitou de valores da ordem de $\mathrm{R} \$ 85 \mathrm{MWh}^{-1}$ para uma TIR de 0\%.

Com relação ao VPN, a Cogeração Básica necessitou de valores próximos a $\mathrm{R} \$ 168$ $\mathrm{MWh}^{-1}$ para igualar ao CAPEX; para cogeração otimizada, $\mathrm{R} \$ 256$ com tratamento de POME, e a maximização energética necessitou de $\mathrm{R} \$ 277 \mathrm{MWh}^{-1}$.

Um dos desafios é a operação ininterrupta em plena capacidade ao longo do ano, dado que a planta de óleo opera em função da produção da área agrícola (disponibilidade de cachos de frutos frescos), que tem seu pico durante a safra $\left(4000\right.$ horas ano $\left.{ }^{-1}\right)$, com diminuição fora desta época. Por outro lado, a produção de biodiesel pode/deve ocorrer durante o ano todo, no que pode fazer uso de outros insumos, como no caso do sebo bovino que, no Brasil, cresce a preços competitivos (NOGUEIRA, 2011).

É oportuno lembrar que a lagoa de tratamento dos resíduos líquidos (POME) é uma das principais fontes de emissões de Gases de Efeito Estufa, e que a devida destinação do metano 
gerado deveria fazer parte de uma eventual política de incentivo à valorização energética dos resíduos da indústria de óleo de Dendê no Brasil, sem, porém, solapar a viabilidade econômica, como visto no cenário Cogeração otimizada + POME - ou seja, garantindo-se a sua adicionalidade (TEIXEIRA, 2006).

Inserindo os dados da comercialização dos créditos de carbono nos resultados econômico financeiros, os resultados podem ser vistos na Tabela 4 e Tabela 5.

\section{Tabela 4 - Impacto advindo da venda de créditos de carbono para as cinco configurações.}

\begin{tabular}{|c|c|c|c|}
\hline \multirow[b]{2}{*}{ Cenário } & \multirow{2}{*}{$\begin{array}{l}\text { Custo Emissão } \\
\text { Reduzida } \\
{\left[{ }^{-1} \$ \text { TCO }_{\text {2equiv. }}{ }^{-1}\right]}\end{array}$} & \multicolumn{2}{|c|}{ Renda Anual $\left[\mathrm{R} \$\right.$ ano $\left.^{-1}\right]$} \\
\hline & & $\begin{array}{c}\text { Mercado } \\
\text { Voluntário }\end{array}$ & Mercado Kyoto \\
\hline Cogeração Básica & 1.297 & 7.197 & 3.119 \\
\hline Cogeração Otimizada & 184 & 241.996 & 419.459 \\
\hline Cogen. Otim. + POME & 153 & 368.000 & 159.467 \\
\hline Cogen. Otim. +Ger. Gás & 158 & 393.349 & 170.451 \\
\hline Maximização Energética & 400 & 626.201 & 271.354 \\
\hline
\end{tabular}

\section{Tabela 5 - Resultados das simulações para as cinco configurações, performance econômica financeira.}

\begin{tabular}{ccccc}
\hline \multirow{2}{*}{ Cenário } & \multicolumn{3}{c}{ Impacto Econômico / Financeiro do projeto (variação) } \\
\cline { 2 - 5 } & Kyoto & \multicolumn{3}{c}{ Voluntário } \\
\cline { 2 - 5 } & TIR [\%] & VPL & TIR [\%] & VPL \\
\hline Cogeração Básica & $2,76(-60 \%)$ & $-0,81(-134 \%)$ & $6,41(-18 \%)$ & $-0,41(-58 \%)$ \\
Cogeração Otimizada & $5,22(173 \%) \%$ & $-2,54(36 \%)$ & $4,27(45 \%)$ & $-2,94(-117 \%)$ \\
Cogen. Otim. + POME & $-0,80(-50 \%)$ & $-6,31(3,6 \%)$ & $1,93(-444 \%)$ & $-4,98(-79 \%)$ \\
Cogen. Otim. +Ger. Gás & $1,00(244 \%)$ & $-6,03(4,5 \%)$ & $3,36(307 \%)$ & $-4,64(-77 \%)$ \\
Maximização Energética & $-0,55(-45 \%)$ & $-6,31(77 \%)$ & $0,43(261 \%)$ & $-4,98(-79 \%)$ \\
\hline
\end{tabular}

Claramente, a comercialização das emissões não se apresenta como um grande diferencial para incentivar a geração de excedentes de energia elétrica junto à indústria de óleo de Dendê, de forma que este não poderá ser apontado como um incentivador para projetos de aumento da geração de energia elétrica para este setor do Agribusiness Brasileiro (em contraponto ao que representou no incentivo à cogeração no setor sucroalcooleiro).

Comparando os dois cenários com tratamento dos resíduos líquidos (POME), foram onde o comércio das emissões teve o maior impacto positivo, indicando que qualquer que seja a política de incentivo ao tratamento dos efluentes líquidos, os instrumentos desenvolvidos não podem torná-la obrigatória (a redução das emissões associadas ao tratamento do POME; com ou sem o aproveitamento energético); visto que isso levaria à impossibilidade de comercialização dos créditos, em função da perda de sua adicionalidade (condição necessária para emissão dos créditos, tanto no mercado regulado quanto no voluntário).

Essa adicionalidade - ou quanto o projeto se distancia do businees as ususal - podemos tomar uma lista de projetos que somente foram implementados com a alavancagem financeira do 
serem enquadrados como MDL (Mecanismo de Desenvolvimento Limpo), assim como algumas de suas características (UNEP, 2012):

PTMM - 26,4 MWe - Ciclo Vapor - 5 Caldeiras 40 bar(g) @ $380{ }^{\circ} \mathrm{C}$ - 210 t vap/hora turbinas condensação: 7, 9,8, 4 e 2,4 - contra pressão 3,2 bar. Sistema de unidades inclui unidade de Óleoquímica. Não foi registrado (Redraw) (DNV, 2007);

Mensilin- 2007 - 24 MWht (térmico) - Vapor para processo em Distrito industrial - 1 caldeira $25 \mathrm{bar}(\mathrm{g}) @ 226{ }^{\circ} \mathrm{C}-31 \mathrm{t}$ vapor hora ${ }^{-1}$. Queima de $10 \mathrm{t} \mathrm{hr}^{-1}$ de cachos vazios e $1,7 \mathrm{t} \mathrm{h}^{-1}$ de madeira (resíduos indústria de móveis). Pré-tratamento dos cachos com trituração e secagem para um mínimo de $43 \%$ de umidade em unidades de pré tratamento com capacidade de $7 \mathrm{t}$ cachos vazios $\mathrm{h}^{-1}$ com 75 a $100 \mathrm{~kW}$ de potência instalada - investimento de 8,0 MUS\$ - 332,9 $\mathrm{US} \$ \mathrm{kWht}^{-1}(\mathrm{DNV}, 2005)$;

Listrindo Kencana - 2007 - Ciclo Vapor - 2 x $6 \mathrm{MW}-2$ caldeiras 38,2 bar a $450{ }^{\circ} \mathrm{C}-35$ $\mathrm{t}$ vap hora ${ }^{-1}$ - Turbinas de condensação de $6 \mathrm{MW}$, com 1,2 MW de consumo parasítico- 8,4 MUS\$ - 700 US\$ kW-1 (7000 ha de plantação) (TÜV-SÜD, 2006).

Assim fica claro que o mercado de emissões - sozinho - não será capaz de maximizar a valorização energética e minimização dos impactos ambientais (aqui representada pelas emissões), da indústria de óleo de Dendê.

Em termos de novas práticas agrícolas, a opção de incorporação dos cachos de frutos vazios no solo, pode levar à proliferação de insetos, com o agravante de apresentarem um grande volume para baixa quantidade de nutrientes; com o registro de algumas tentativas de compostagem utilizando POME (SILALERTRUKSA \& GHEEWALA, 2012).

Os dois cenários com maior impacto econômico financeiro foram os: Cogeração Otimizada e Cogeração Otimizada com Tratamento de POME e grupos geradores usando o Biogás. Para todos os demais, o impacto, de fato, foi negativo (diminuindo a TIR), ainda que com um melhor desempenho financeiro (melhoraram o Valor Presente Líquido, mas sem ser significativo). Para todos os cenários, os altos custos de implantação e monitoria do projeto acabaram por pesar no desempenho econômico financeiro.

Uma análise interessante, é que os ganhos com a venda de excedentes de eletricidade são feitas no mercado interno, de forma que se apresenta, para o setor, como uma renda não exposta à variação do preço do Óleo de Dendê no mercado internacional de commodity, sempre sujeita à alta volatilidade (GONTIJO et al., 2012)

\section{Conclusões}

Com base nos números encontrados, fica demonstrada a viabilidade econômica com baixa atratividade para algumas das tecnologias de geração de excedentes de eletricidade junto à agroindústria de extração de óleo de dendê no Brasil, a qual pode ser incentivada com a adoção de politicas públicas adequadas, e/ou amparo à adoção de tecnologias específicas (formulação de políticas setoriais, e incentivos governamentais).

Exemplos destas políticas seriam: adoção de patamares mínimos para a geração do vapor para financiamento de sistemas de cogeração, regulamentação da necessidade de tratamento dos efluentes líquidos - POME, com destruição do metano, onde o direcionamento para motores de combustão interna leva à valores positivos de retorno do capital.

Ainda que, em muitos casos, seja economicamente viável, ela ainda não é financeiramente atrativa, não representando boa opção para recuperação do capital investido (Valor Presente 
Líquido negativo). Neste sentido, deveriam ser formuladas políticas de incentivo à valorização energética dos resíduos desta indústria, no Brasil, em especial por poder apresentar contraponto à geração de eletricidade com biomassa de cana para a região sudeste (dado que a maior parte da produção de dendê fica fora desta região, o também chamado "vazio amazônico").

Ficou claro também que a maior atratividade foi para os cenários com emprego de tecnologias já dominadas pelo mercado brasileiro (turbinas de extração-condensação), não devendo ser necessário o uso de tecnologias ainda não consolidadas no setor, como no Cenário Maximização Energética.

Um elemento que deveria ser mais bem estudado é a questão da queima direta (ou com prétratamento), dos cachos após a extração dos frutos (EFB - Empty Fruit Brunches), que a indústria nacional possa apresentar uma resposta a este desafio para a indústria de óleo de palma mundial.

\section{AGRADECIMENTOS}

$\mathrm{O}$ autor agradeceu aos diversos fabricantes de equipamentos que forneceram dados de funcionamento e custos à vários dos sistemas considerados, em especial ao Sr. Daniel Honda, da Sansuy Ltda. ${ }^{1}$.

\section{REFERÊNCIAS}

Arrieta, F.; Teixeira, F.; Yáñez, E.; Lora, E.; Castilho, E. Cogeneration potential in the Columbian palm oil industry: Three case studies. Biomass and Bioenergy, 31, p. 503-511, 2007. http://dx.doi.org/10.1016/j.biombioe.2007.01.016.

Aun, Khoo Hock. Biodiesel Big Picture: lessons learned in biodiesel developments in Malaysia. World Biofuels Market. Amsterdam, Netherland, 16 de Março, 2010. Available at: http://www.biomass-asia-workshop.jp/biomassws/04workshop/presentation_files/09_ Wahono.pdf e apresentação 2012 Congresso Amsterdam. Disponível em: http://www. jatropha.pro/PDF\%20bestanden/khoo_hock_aun.pdf.

CCEE. CCEE - Info PLD - Preço de Liquidação das Diferenças - PLD. CCEE, 2014. Disponível em: http://www.ccee.org.br/portal/faces/pages_publico/o-que-fazemos/ como_ccee_atua/precos/info_pld?_afrLoop=1023359783079884, acessada em 06/2014.

Chiew, Y. L.; Tomoko, I.; Sohe, S. System analysis for effective use of palm oil waste as energy resources. Biomass and Bioenergy, 35, p. 2925-2935', 2011. http://dx.doi. org/10.1016/j.biombioe.2011.03.027.

Cortez, L; Magalhães, P.; Happ, J. Principais subprodutos da agroindústria canavieira e sua valorização. Revista Brasileira de Energia, v.2, p.111-146,1992.

I A menção de marcas não representa recomendação por parte do autor. 
SILVA, C. L. da; RABELO, J. M.; RAMAZZOTTE, V. d.; Rossi, L. F.; Bollamann, H. A. A cadeia de biogás e a sustentabilidade local: uma análise socioeconômica ambiental da energia de resíduos sólidos urbanos do aterro da Caximba em Curitiba. Inovar (On line), vol. 19 nu, 34, Maio - Agosto, p. 83-98, 2009. Disponível em: <http://www.scielo. org.co/scielo.php?script=sci_arttext\&pid=S0121-50512009000200007\&lng=en\&nrm= iso >. ISSN 0121-5051.

DNV. Mensilin Holdings Biomass Energy Plant Project. Version 3. 17 de Maio, 2005. Disponível em: http://www.dnv.com/focus/climate_change/Upload/Mensilin\%20 PDD\%20version\%202,\%2017-05-07.pdf.

DNV. PDD - PTMM Biomass to Electricity Project 26.4 MW(e). Version 1.0, 1 March 2007. Disponível em: http://www.dnv.com/focus/climate_change/upload/pdd\%20 12-03-07final.pdf.

Garcia, Laura Fernandes; Conejero, Marco Antônio; Neves, Marcos Fava. Biodiesel: um olhar para o futuro com base nos 30 anos do Proalcool. In: Anais XLV Congresso da SOBER - Congresso da Sociedade Brasileira de Economia, Administração e Sociologia Rural. UEL: Londrina, 22 a 25 de Julho 2007.

Garcia-Nunez, Jesus Alberto; Ramirez-Contreras, Nidia Elizabeth; Rodriguez, Deisy Tatiana; Silva-Lora, Electo; Frear, Craig Stuart; Stockle, Claudio; Garcia-Perez, Manuel. Evolution of palm oil mills into bio-refineries: Literature review on current and potential uses of residual biomass and effluents. Resources, Conservation and Recycling, vol. 110, July 2016, Pages 99-114. Disponível em: https://doi.org/10.1016/j.resconrec.2016.03.022.

Gontijo, T.S.; Fernandes, E.A; Saraiva, M.B. Análise da volatilidade do retorno da commodity dendê: 1980-2008. Revista de Economia e Sociologia Rural, Brasília , v. 49, n. 4, Dec. 2011. http://dx.doi.org/10.1590/S0103-20032011000400003.

Hamrick, Kelley; Gallant, Melissa. Unlocking Potential: State of the Voluntary Carbon Markets 2017.Washington: Forest Trends'Ecosystem Marketplace, 2017. Disponível em: https://www.forest-trends.org/wp-content/uploads/2017/07/doc_5591.pdf.

Hansen, S. B.; Olsen, S. I.; Ujang, Z. Greenhouse gas reductions through enhanced use of residues in the life cycle of Malaysian palm oil derived biodiesel. Bioresource Technollgy, 104, p. 358-366, 2012. http://dx.doi.org/10.1016/j.biortech.2011.10.069.

Husain, Z.; Zainal, Z.; Abdullah, M. Analysis of biomass-residue-based cogeneration system in palm oil mills. Biomass and Bioenergy, 24, p. 117 - 124. 2003. http://dx.doi. org/10.1016/S0961-9534(02)00101-0. 
IRG.Scoping Studyon Clean Technology Opportunities andBarriersinIndonesian Palm OilMilland Rice Mill Industries - Final Report.IFC - International Finance Cooperation: Filipines. 2011. Disponível em: http://www.ifc.org/wps/wcm/connect/8894fe804726241c945cbf2b131be d2a/Scoping\%2Bstudy\%2Bclean\%2Btechnology\%2Bopportunities\%2Bin\%2BIndonesia. pdf?MOD=AJPERES.

Joo-Hwa, T.; Kuan-Yeow, S. Use of ash derived from oil-palm waste incineration as a cement replacement material. Resources, Conservation and Recycling, 13, p. 27-36, 1995. http://dx.doi.org/10.1016/0921-3449(94)00012-T.

Kamahara, H.; Hasanudin, U.; Widiyanto, A., Tachibana, R., Atsuta, Y., Goto, N., et al. Improvement potential for net energy balance of biodiesel derived from palm oil: A case study from Indonesian practice. Biomass and Bioenergy, 34, p. 1818-1824, 2010. http:// dx.doi.org/10.1016/j.biombioe.2010.07.014.

Khatun, Rahima; Reza, Mohammad Imam Hasan; Moniruzzaman, M.; Yaakob, Zahira. Sustainable oil palm industry: The possibilities. Renewable and Sustainable Energy Reviews, vol. 76, Sep 2017, pg 608-619. Diponível em: https://doi.org/10.1016/j. rser.2017.03.077.

Mahlia, T.; Abdulmuin, M.; Alamsyah, T.; Mukhlishien, D. An alternative energy source from palm waste industry for Malaysia and Indonesia. Energy Conversion and Management, 42, p. 2109-2118, 2001. http://dx.doi.org/10.1016/S0196-8904(00)00166-7.

Man, L. K.; Keat, L. T. Renewable and sustainable bioenergies production from palm oil mill effluent (POME): Win-win strategies toward better environmental protection. Biotechnology Advances, 29, p. 124-141, 2011. http://dx.doi.org/10.1016/j. biotechadv.2010.10.001.

MCTI. Fatores de Emissão de CO2 de acordo com a ferramenta metodológica: "Tool to calculate the emission factor for an electricity system, versions 1, 1.1, 2, 2.1.0 and 2.2.0" aprovada pelo Conselho Executivo do MDL. Disponível em: http://www.mct.gov.br/index.php/content/ view/74689.html. Acesso em 08/2013.

Nogueira, L.A. Does biodiesel make sense? Energy, 36, p. 3659-3666,2011.http://dx.doi. org/10.1016/j.energy.2010.08.035.

Paulillo, Luiz Fernando; Vian, Carlos Eduardo De Freitas; Shikida, Pery Francisco Assis; Mello, Fabiana Tanoue de. Álcool combustível e biodiesel no Brasil: quo vadis?. Rev. Econ. Sociol. Rural [online]. 2007, vol.45, n.3, pp. 531-565. ISSN 0103-2003. Disponível em: http://www.scielo.br/pdf/resr/v45n3/a01v45n3.pdf. 
Pleanjai, S.; Gheewala, S.; Garivait, S. Environmental Evaluation of Biodiesel Production from Palm Oil in a Life Cycle Perspective. Asian Journal of Energy Environment, 8, nu. 1 and 2, p. 15-32, 2007. Disponível em: http://www.jseejournal.com/AJEE\%202007/3. Environmental\%20evaluation\%20p.15-32.pdf.

Poh, P., \& Chong, M. Development of anaerobic digestion methods for palm oil mill effluent (POME) treatment. Bioresource Technology, 100, 1, p. 1-9, 2009. http://dx.doi. org/10.1016/j.biortech.2008.06.022.

Proença, L. Projeto Granja São Roque de Redução de Emissão de GEE - DCP. São Paulo: B. C. 1tda, Ed. São Paulo, Brasil, 2009. Disponível em: http://www.gsaoroque.com.br/ projetogranjasaoroque/DCP.pdf.

Queiroz, A.G.; França, L.; Ponte M.X. The life cycle assessment of biodiesel from palm oil ("dendê") in the Amazon. Biomass and Bioenergy, 36, p. 50-59, 2011. http://dx.doi. org/10.1016/j.biombioe.2011.10.007

Shahrakbah, Y.; Mohd, A. H.; Yoshihito, S.; Minato, W.; Sunderaj, S. Baseline study of methane emission from open digesting tanks of palm oil mill effluent treatment. Chemosphere, 59, p. 1575-1581, 2005. http://dx.doi.org/10.1016/j.chemosphere.2004.11.040.

Shikida, Pery Francisco Assis and PEROSA, Bruno Benzaquen. Álcool combustível no Brasil e path dependence. Rev. Econ. Sociol. Rural [online].2012, vol.50, n.2, pp. 243-262. ISSN 0103-2003. Disponível em: http://www.scielo.br/pdf/resr/v50n2/v50n2a03.pdf.

Shuit, S.; Tan, K.; Lee, K.; Kamaruddin, A. Oil palm biomass as a sustainable energy source: A Malaysian case study. Energy, 34, p. 1225-1235, 2009. http://dx.doi.org/10.1016/j. energy.2009.05.008.

Silalertruksa, T.; Gheewala, S. Environmental sustainability assessment of palm biodiesel production in Thailand. Energy, 43, 1, p. 306-314, 2012. http://dx.doi.org/10.1016/j. energy.2012.04.025.

Teixeira, M. A.; Palacio, J. C.; Sotomonte, C. R.; Lora, E. E.; Aßmann, D. ASSAÍ An Energy View on an Amazon Residue. Biomass and Bioenergy, 2013. http://dx.doi. org/10.1016/j.biombioe.2013.08.007.

Teixeira, M. A. Mecanismos de Desenvolvimento Limpo, critério de Adicionalidade e suas repercussões. Revista Portuguesa e Brasileira de Gestão 5 (2), 36-46, 2006.

Tonin, João Ricardo; Tonin, Julyerme Matheus. Do Proálcool ao "Próetanol": novos desafios na produção do etanol brasileiro. Informe GEPEC. Vol. 18, No 1, 2014. Disponíel em: http://e-revista.unioeste.br/index.php/gepec/article/download/10342/7445. 
TÜV-SÜD. PDD - Listrindo Kencana Biomass Power Plant. Version 7.0.0, 07 May 2008. Disponível em: http://www.netinform.net/KE/files/pdf/P0201J_PDD_Version_7.1_ Listrindo_RepeatII.pdf.

UNEP. UNEP Risoe CDM/JI Pipeline Analysis and Database. Risoe: UNEP, 2012. Disponível em: http://www.cdmpipeline.org/.

UNFCCC. AMS-III.H.: Methane recovery in wastewater treatment. Version 16, 2010. Disponível em: https://cdm.unfccc.int/methodologies/DB/4ND00PCGC7WXR3L0L OJTS6SVZP4NSU, acesso em 27/10/2014.

UNFCCC. Clean Development Mechanism - TOOL07: Methodological tool/Tool to calculate the emission factor for an electricity system. Version 04.0,2013. Disponível em: https://cdm. unfccc.int/methodologies/PAmethodologies/tools/am-tool-07-v4.0.pdf.

Yasin, Mohd Hafizil Mat; Mamat, Rizalman; Najafi, G.; Ali, Obed Majeed; Yusop, Ahmad Fitri; Ali, Mohd Hafiz. Potentials of palm oil as new feedstock oil for a global alternative fuel: A review. Renewable and Sustainable Energy Reviews. Vol. 79, November 2017, Pages 1034-1049. Disponível em: https://doi.org/10.1016/j.rser.2017.05.186. 